\title{
Varicocele: Evaluation and treatment
}

\author{
Armand Zini MD
}

\begin{abstract}
A Zini. Varicocele: Evaluation and treatment. J Sex Reprod Med 2002;2(3):119-124.

Varicocele is the most common identifiable pathology in infertile men. It is present in $15 \%$ of the male population, in approximately $35 \%$ of men with primary infertility and in $50 \%$ to $80 \%$ of men with secondary infertility. It is generally accepted that varicocele exerts a negative influence on spermatogenesis and steroidogenesis, primarily by elevating testicular temperature. However, the effect of varicocelectomy on the restoration of testicular function and fertility in adults is the subject of ongoing controversy. Microsurgical varicocelectomy has been advocated as the 'gold standard' method, based on the low complication rate associated with this procedure. In the era of advanced assisted reproduction, varicocelectomy is a valuable tool in the management of infertile men.
\end{abstract}

Key Words: Assisted reproduction; Male infertility; Spermatogenesis; Varicocele; Varicocelectomy

\section{Varicocèle : Évaluation et traitement}

RÉSUMÉ : La varicocèle est la pathologie identifiable la plus répandue chez les hommes infertiles. Elle s'observe chez $15 \%$ de la population masculine, chez environ $35 \%$ des hommes ayant un problème d'infertilité primaire et chez 50 à $80 \%$ des hommes ayant une infertilité secondaire. On s'entend en général pour dire que la varicocèle exerce une influence négative sur la spermatogenèse et sur la stéroïdogenèse, principalement par le biais d'une élévation de la température des testicules. Par contre, l'effet de l'ablation de la varicocèle sur le rétablissement de la fonction testiculaire et de la fertilité chez les adultes fait toujours l'objet d'une controverse. L'ablation de la varicocèle par microchirurgie a été proposée comme méthode standard sur la base du faible taux de complications qui lui est associé. À l'ère des technologies de reproduction de pointe, l'ablation de la varicocèle est un outil utile pour le traitement des hommes infertiles.
$\mathrm{V}$ aricocele is defined as dilated testicular veins in the scrotum, and is the most common identifiable pathology in infertile men. Although it is accepted that varicocele exerts a negative influence on male fertility potential, the effect of varicocelectomy on the restoration of fertility in men is the subject of ongoing controversy. The present article is not intended to resolve controversial issues regarding varicocele, but rather should provide the reader with a basic overview of the subject, with emphasis on the pathophysiology, diagnosis and treatment of this condition.

\section{INCIDENCE}

The incidence of varicocele in the general male population is approximately $15 \%(1-4)$. The incidence in men present- ing for infertility is about $35 \%$, and in men with secondary infertility it is $50 \%$ to $80 \%(5-7)$. Although varicocele is almost always larger and more common on the left side $(5,8)$, the incidence of bilateral varicocele is approximately $50 \%$. The rare, isolated, right-sided varicocele generally suggests that the right internal spermatic vein enters the right renal vein, but it should prompt further investigation because this finding may be associated with situs inversus or retroperitoneal tumours. Oster (9) observed that no varicocele was detected in 188 boys six to nine years of age, but was detected with increasing prevalence in boys 10 to 14 years of age, suggesting that varicocele develops at puberty (9). More recently, it has been shown that the prevalence of varicocele in young boys is associated directly with the lev-

Division of Urology, Department of Surgery, Mount Sinai Hospital, University of Toronto, Toronto, Ontario

Correspondence: Dr Armand Zini, Division of Urology, Suite 1525, Mount Sinai Hospital, 600 University Avenue, Toronto, Ontario M5G 1 X5.

Telephone 416-586-4613, fax 416-586-8354, e-mail azini@mtsinai.on.ca 
el of sports-related activity (soccer playing), suggesting that varicocele may develop as a result of increased intraabdominal pressure during childhood and puberty (10).

The significantly higher incidence of varicocele in men with secondary infertility, coupled with the observation that varicocele generally develops at the time of puberty, suggests that the presence of varicocele can cause a progressive decline in fertility $(6,7)$. This implies that men with varicocele and previous fertility are not immune from potential ongoing varicocele-mediated testicular injury. Although the high incidence of varicocele in the general male population indicates that many, or even most, men with varicocele are fertile (at least when they are younger), a prospective study has shown that semen quality declines in men with untreated varicocele (11). Johnson et al (3) showed that, in a cohort of asymptomatic military recruits, nearly $70 \%$ of men with a palpable varicocele had an abnormality on semen analysis.

\section{ETIOLOGY}

The etiology of varicocele is probably multifactorial. The anatomical differences between the left and right internal spermatic veins, the absence or incompetence of venous valves resulting in the reflux of venous blood, and increased hydrostatic pressure are among the most likely causes of varicocele. The left vein is approximately 8 to $10 \mathrm{~cm}$ longer than the right, and this is believed to result in an increase in hydrostatic pressure (12). This pressure is transmitted to the internal spermatic vein at the level of the pampiniform plexus, causing dilation of the veins. The report by Braedel et al (13) on the venographic pattern of 659 consecutive men with varicocele revealed that the majority of these men (484 of 659) had absent venous valves. Compression of the left renal vein between the aorta and the superior mesenteric artery ('nutcracker effect') may also contribute to the increased internal spermatic venous pressure. A number of radiological studies have documented a relative distension of the proximal left renal vein, suggesting partial distal obstruction (14).

\section{MECHANISMS}

A number of theories have been proposed to explain the observed pathophysiology of varicocele. Increased scrotal temperature has been demonstrated in humans with varicocele and in animals with surgically induced varicocele, and is the most widely accepted mechanism believed to be responsible for varicocele-induced pathology (15). The meticulous work of Zorgniotti and Macleod (15) revealed that men with varicocele have higher intrascrotal temperatures than do controls. However, the observed elevation in intrascrotal temperatures in men with varicocele is probably nonspecific because men with idiopathic infertility also often demonstrate elevated intrascrotal temperature readings. The sensitivity of spermatogenesis to temperature elevations supports the mechanistic theory (15-17).

The theory of adrenal and renal metabolite reflux stems from early anatomical radiographic studies documenting the reflux of blood from the renal vein into the internal spermatic vein. Despite the reports demonstrating correlations between increased concentrations of these metabolites in the internal spermatic vein and the presence of varicocele, few of these metabolites have been clearly shown to be gonadotoxic (18-20). Increased hydrostatic pressure in the internal spermatic vein from renal vein reflux may be an additional mechanism for varicoceleinduced pathology (11).

\section{PATHOPHYSIOLOGY}

This section outlines the main features of varicoceleassociated pathophysiology.

\section{Testicular atrophy}

Testicular atrophy has been well documented in men with varicocele. Lipschultz and Corriere (21) demonstrated that the left testicular size in men with a left varicocele was significantly decreased compared with controls without varicocele. The World Health Organization (WHO) (11) presented similar results in a multicentre study that evaluated the physical findings and semen characteristics of men presenting for infertility. The WHO study reported that varicocele (most of which were on the left side) was associated with relative left testicular atrophy compared with the contralateral testis. Using scrotal ultrasonography to accurately measure testicular volume, left varicocele has been shown to be associated with relative left testicular atrophy (22). In contrast, it was reported that right and left testicular volume was not significantly different in men without varicocele (22).

\section{Testicular histology and biochemical function}

A number of studies have attempted to characterize the changes in testicular histology associated with varicocele (23-27). Most of these studies documented the bilateral nature of these changes. The histological findings have ranged from normal spermatogenesis to Sertoli cell only pattern, with most studies reporting varying degrees of hypospermatogenesis. Additionally, histological features that have been identified in a number of studies include premature sloughing of germ cells into the seminiferous tubule lumen and Leydig cell hyperplasia (23).

\section{Leydig cell function}

Leydig cell dysfunction has been documented in men with varicocele. A WHO multicentre study (11) on the influence of varicocele on fertility parameters demonstrated that the mean testosterone concentration of men older than 30 years of age with varicocele was significantly lower than that of younger patients with varicocele, whereas this trend was not observed in men without varicocele. Comhaire and Vermeulen (28) evaluated 10 patients with decreased testosterone, impotence and varicocele, and observed that, after varicocelectomy, the serum testosterone increased in all cases. Su et al (29) also observed a significant increase in mean testosterone levels after 
varicocelectomy in a group of 53 infertile men with varicocele.

\section{Semen characteristics and sperm function}

Semen parameter abnormalities in infertile men with varicocele were first described by Macleod in 1965 (30). In that study, Macleod observed that the vast majority of semen samples, obtained from 200 infertile men with varicocele, had an increased number of abnormal forms, decreased motility and lower mean sperm counts. This 'stress pattern', which is also characterized by an increased number of tapered forms and immature cells, may not be specific to varicocele (31-34).

\section{DIAGNOSIS}

Varicocele is generally diagnosed on physical examination. A warm examining room, promoting relaxation of the scrotal dartos muscle, facilitates accurate evaluation for varicocele. Varicocele grades are defined as follows: grade I palpable only with Valsalva; grade II - palpable without Valsalva; and grade III - visible.

A number of modalities have been used to diagnose varicoceles, including venography, Doppler stethoscope, radionuclide angiography, scrotal thermography and scrotal ultrasonography. The availability, reproducibility and noninvasiveness of scrotal ultrasonography have led to its increased use in the diagnosis of varicocele. However, the significance of subclinical varicocele (one that is not clinically palpable) remains controversial (35). The lack of standardized criteria for diagnosis and the conflicting treatment outcome reports on subclinical varicocele raise questions about the existence and significance of this entity.

\section{VARICOCELECTOMY}

\section{Indications}

Varicocelectomy is indicated in men with clinical varicocele, abnormal semen parameters and couple infertility. This is based on the demonstration that varicocele is associated with a progressive decline in testicular function and that the repair of varicocele can improve spermatogenesis (36-39). Varicocelectomy is also indicated in men with clinical varicocele and testicular pain $(40,41)$. Typically, the pain is throbbing in nature, is localized to the testis and/or varicocele, and is worse with increased physical activity. Finally, varicocelectomy is indicated in the child or adolescent with clinical varicocele and decreased ipsilateral testicular volume (greater than $2 \mathrm{~mL}$ difference between the right and left testis) (42-44).

\section{Techniques}

A variety of surgical approaches have been advocated for varicocelectomy, including retroperitoneal and conventional inguinal open techniques, microsurgical inguinal and subinguinal approaches, laparoscopic repairs and radiographic embolization. The importance of using a varicocelectomy technique that minimizes the risk of complications and recurrences cannot be overemphasized. The microsurgi- cal technique, regarded as the 'gold standard', is described $(45,46)$.

The subinguinal microsurgical varicocelectomy is the most popular surgical approach. The advantages of this approach are that it enables the surgeon to easily identify the spermatic cord structures, and, if necessary, access the testis, epididymis and the external spermatic and gubernacular veins with the delivery of the testis.

The subinguinal approach described by Marmar and Kim (45) obviates the need for opening any fascial layer, and, as a result, is associated with less postoperative pain and a more rapid recovery. However, at the subinguinal level, significantly more veins are encountered, the artery is more often surrounded by a network of tiny veins that must be ligated, and the testicular artery has often divided into two or three branches, making its identification and preservation more difficult.

The subinguinal microsurgical varicocelectomy begins with a 2 to $3 \mathrm{~cm}$ oblique skin incision centred over the external inguinal ring. The incision is deepened through Camper's and Scarpa's fascias, and the spermatic cord is then grasped with a nontraumatic ring clamp, delivered and placed over a large ( $\left.1^{\prime \prime}\right)$ silastic drain. The testicle is then delivered, and the gubernacular veins and external spermatic perforators are isolated and divided. The testicle is returned to the scrotum and the spermatic cord is elevated on a large Penrose drain. The microscope is then brought into the operating field and the cord is examined under eight to 15 power magnification. The internal and external spermatic fascias are incised longitudinally and the cord structures are again examined.

The contents of the spermatic cord are then dissected under microscopic control. Subtle pulsations usually reveal the location of the underlying internal spermatic artery or arteries. Once identified, the artery is dissected free of all surrounding veins and encircled with a 2-0 silk ligature or vessel loop for identification. Care is taken to identify a number of lymphatics (usually two to five channels are preserved) and these are also encircled with a 2-0 silk ligature or vessel loop. All internal and external spermatic veins are clipped or ligated (with 4-0 silk) and divided. The vas deferens and its associated vessels are readily identified and preserved. At the completion of varicocelectomy, the cord should contain only the testicular artery or arteries, vas deferens, and associated vessels (artery and vein) and spermatic cord lymphatics. The wound is irrigated with $1 \%$ neomycin irrigation, and Scarpa's and Camper's fascias are closed with a single 3-0 chromic catgut suture. The incision is infiltrated with $0.5 \%$ marcaine solution with adrenaline and the skin is closed with a running 4-0 vicryl subcuticular closure reinforced with steristrips. A dry, sterile dressing is applied.

\section{Outcomes}

A large number of studies have evaluated the outcome of varicocelectomy on fertility parameters, and most of these studies have demonstrated an improvement in semen qual- 
ity and pregnancy rates (39). However, because the bulk of the reported outcome data on varicocelectomy comes from uncontrolled or poorly designed controlled studies, the value of these results is limited (39). In addition, the few reports comparing the various treatment options have not shown convincingly the superiority of one method over another. Overall, varicocelectomy results in significant improvement in semen analysis in $60 \%$ to $80 \%$ of men, and pregnancy rates after varicocelectomy vary from $20 \%$ to $60 \%$ (39). In Kamal et al's (47) report of close to 200 microsurgical operations, nearly $50 \%$ of couples were pregnant at two years' follow-up and the most important predictor of successful outcome was the initial sperm concentration. Pregnancy rates were $60 \%$ in those couples in whom the man's initial sperm concentration was greater than 5 million $/ \mathrm{mL}$ and only $8 \%$ when the man's initial sperm concentration was $5 \mathrm{million} / \mathrm{mL}$ or less.

Only a relatively small number of controlled studies (mostly nonrandomized) have evaluated the outcome of varicocelectomy on male fertility potential. About half of those studies showed significantly higher pregnancy rates in the treatment arm (39). The obvious flaw with the studies was that the control groups were not the same as the treatment groups. Indeed, in most of these studies, men who refused surgery (and, therefore, were possibly less motivated) served as controls.

Similarly, the outcome of controlled, randomized studies has been variable (48-52). In 1979, Nilsson et al (48) reported lower pregnancy rates for men treated by varicocelectomy $(n=51)$ compared with 45 randomized controls. The major criticisms of this study were the wide standard deviations, the wide variations in the serial semen analyses and the remarkably low pregnancy rates reported. Laven et al (49) evaluated the results of varicocelectomy in adolescents with varicoceles $(n=67)$ in a prospective randomized fashion. They demonstrated improved semen parameters in the surgically treated group, but not in the control group. Unfortunately, due to the patient population, Laven et al could not assess the effect of varicocelectomy on fertility. Nieschlag et al (50) reported no significant difference in pregnancy rates between the control $(n=48)$ and treatment $(n=47)$ arms, although semen parameters improved significantly only in the treatment arm. Nieschlag et al's (51) larger follow-up study reported similar results. In perhaps the best randomized, crossover study, Madgar et al (WHO-sponsored) (52) demonstrated significantly higher pregnancy rates in the early and delayed varicocelectomy groups than in the control, nonoperated group. The major weakness of the Madgar study was the small sample size $(n=45)$.

\section{Varicocelectomy and azoospermia}

Studies have indicated that there may be some benefit in repairing varicoceles in infertile men with azoospermia and clinical varicocele $(53,54)$. Although significant improvement in semen quality (appearance of sperm in the semen) is reported in approximately $50 \%$ of these men, a clinically significant outcome (with spontaneous pregnancy) is reported in less than $20 \%$ of these cases $(53,54)$. Preoperative testicular biopsy is predictive of the outcome in these cases. Only men with mature spermatids or spermatozoa on testicular biopsy had a good outcome (appearance of sperm in the semen). Men with maturation arrest or Sertoli cell only pattern on testicular biopsy remained azoospermic postoperatively (54).

\section{Complications of varicocele repair}

Complications of varicocelectomy (hydrocele, varicocele recurrence, testis atrophy) are technique specific. The microsurgical varicocelectomy is associated with the lowest complication rates and, as such, is considered to be the 'gold standard' approach.

Hydrocele formation is a common complication of nonmicrosurgical varicocelectomy. The incidence of this complication varies from $3 \%$ to $33 \%$, with an average incidence of approximately $7 \%$ (55). The difficulty in identifying and preserving lymphatics using nonmicrosurgical approaches (especially retroperitoneal) results in the development of this complication. Analysis of the hydrocele fluid has clearly indicated that hydrocele formation following varicocelectomy is due to the ligation of the lymphatics (55). The effect of hydrocele formation on sperm function and fertility is unknown. The use of magnification to identify and preserve lymphatics virtually eliminates the development of hydrocele after varicocelectomy $(45,46)$. In addition, radiographic embolization is not complicated by hydrocele formation.

The incidence of testicular artery ligation during varicocelectomy is unknown, but some studies suggest it is common $(56,57)$. The identification and preservation of the 0.5 to $1 \mathrm{~mm}$ testicular artery via the retroperitoneal approach is difficult, especially in children, whose arteries are small. Injury or ligation of the testicular artery carries with it the risk of testicular atrophy and impaired spermatogenesis. Penn et al's (58) transplant group reported a 14\% incidence of frank testicular atrophy when the testicular artery was intentionally ligated. In humans, atrophy after artery ligation is probably unlikely due to the contribution of the cremasteric and vasal arteries. In children, the potential for neovascularization and compensatory hypertrophy of the vasal and cremasteric vessels is probably greater than in adults, making atrophy after testicular artery ligation even less likely. The use of magnifying loupes or, preferably, an operating microscope, facilitates the identification and preservation of the testicular artery and, therefore, minimizes the risk of testicular injury. Radiographic embolization is not complicated by testicular atrophy.

The incidence of varicocele recurrence following surgical repair varies from $0.6 \%$ to $45 \%$. Recurrence is more common after the repair of pediatric varicoceles (59-61). Venographic studies of recurrent varicoceles have identified periarterial, parallel inguinal, midretroperitoneal, or, more rarely, trans-scrotal collaterals (62). Retroperitoneal operations are associated with the highest rate of varicocele recurrence. Recurrence rates after retroperitoneal varicocelectomy are approximately $15 \%(63,64)$. Failure is 
usually due to the preservation of the periarterial plexus of fine veins (venae commitantes). Less commonly, failure is due to the presence of parallel inguinal or retroperitoneal collaterals that may exit the testis, bypass the retroperitoneal area and join the internal spermatic vein proximal to the site of ligation $(65,66)$. Cremasteric veins cannot be identified using a retroperitoneal approach and may be a potential site of varicocele recurrence (67). The recurrence rate after balloon occlusion varies from $4 \%$ to $11 \%$ $(62,65,68,69)$. The microsurgical approach with delivery of the testis lowers the incidence of varicocele recurrence to less than $1 \%(46)$.

\section{Alternative to varicocelectomy - assisted reproduction} For many men with specific causes of male-factor infertility (ie, varicocele), conventional therapy (varicocelectomy) is not successful in restoring fertility potential. Only assisted reproduction (AR) helps these men contribute to a pregnancy. It has recently been reported that a significant percentage of couples in whom the man has undergone a varicocelectomy (approximately 25\%) seek AR, and most of these couples (approximately 80\%) achieve a pregnancy with AR (47). Alternatively, many men opt for AR instead of varicocelectomy in the hope of achieving a more immediate pregnancy.

\section{REFERENCES}

1. Horner JS. The varicocele: A survey among secondary schoolboys. Med Officer 1960;104:377-81.

2. Clarke BG. Incidence of varicocele in normal men and among men of different ages. JAMA 1966;198:1121-2.

3. Johnson DE, Pohl DR, Rivera-Correa H. Varicocele: An innocuous condition? South Med J 1970;63:34-6.

4. Steeno O, Knops J, Declerk L, et al. Prevention of fertility disorders by detection and treatment of varicocele at school and college age. Andrologia 1976;8:47-53.

5. Dubin L, Amelar R. Varicocelectomy: 986 cases in a 12 year study. Urology 1977;10:446-9.

6. Gorelick J, Goldstein M. Loss of fertility in men with varicocele. Fertil Steril 1993;59:613-6.

7. Witt MA, Lipshultz LI. Varicocele: A progressive or static lesion? Urology 1993;42:541-3.

8. Greenberg SH, Lipschultz LI, Wein AJ. Experience with 425 subfertile male patients. J Urol 1978;119:507-10.

9. Oster J. Varicoceles in children and adolescents. Scand J Urol Nephrol 1971;5:27-32.

10. Scaramuzza A, Tavana R, Marchi A. Varicoceles in young soccer players. Lancet 1996;348:1180-1.

11. World Health Organization. The influence of varicocele on parameters of fertility in a large group of men presenting to infertility clinics. Fertil Steril 1992;57:1289-92.

12. Shafik A, Bedeir GA. Venous tension patterns in cord veins. 1. In normal and varicocele individuals. J Urol 1980;123:383-5.

13. Braedel HU, Steffens J, Ziegler M, Polsky MS, Platt ML. A possible ontogenic etiology for idiopathic left varicocele. J Urol 1994;151:62-6.

14. Buschi AJ, Harrison RB, Brenbridge AN, et al. Distended left renal vein: $\mathrm{CT} /$ sonographic normal variant. Am J Radiol 1980;135:339-42.

15. Zorgniotti AW, Macleod J. Studies in temperature, human semen quality, and varicocele. Fertil Steril 1973;24:854-63.

16. Lerchl A, Keck C, Spiteri-Grech J, et al. Diurnal variations in scrotal temperature of normal men and patients with varicocele before and after treatment. Int J Androl 1993;16:195-200.

17. Mieusset R, Bujan L, Mondinat C, et al. Association of scrotal hyperthermia with impaired spermatogenesis in infertile men. Fertil Steril 1987;48:1006-7.
Fortunately, recent advances in AR have revolutionized the management of infertile couples, and in particular, those couples with severe male-factor infertility (70). However, the pregnancy rates with AR (eg, in vitro fertilization [IVF] or intracytoplasmic sperm injection [ICSI]) are modest, with most centres reporting IVF and ICSI pregnancy rates of 30\% to $40 \%$ when female factors are excluded (ie, advanced female age). A study on the cost effectiveness of AR versus varicocelectomy for varicocele-induced infertility suggests that varicocelectomy may be more cost effective than AR (71).

\section{SUMMARY}

Varicocele is a very common entity. It is present in $15 \%$ of the male population, in approximately $35 \%$ of men with primary infertility and in $50 \%$ to $80 \%$ of men with secondary infertility. A substantial body of evidence suggests that a varicocele causes elevated testicular temperature and this results in endocrine and exocrine dysfunction in the testis. There is good evidence to show that varicocele causes a progressive decline in testis function and that varicocelectomy can restore fertility in some men. Refined methods of varicocele repair, namely, the microsurgical technique, have reduced the incidence of complications following varicocelectomy.

18. Comhaire F, Vermeulen A. Varicocele sterility: Cortisol and catecholamines. Fertil Steril 1974;25:88-95.

19. Cohen MS, Plaine L, Brown JS. The role of internal spermatic vein plasma catecholamine determinations in subfertile men with varicoceles. Fertil Steril 1975;26:1243-9.

20. Ito $\mathrm{H}$, Fuse $\mathrm{H}$, Kawamura K, et al. Internal spermatic vein prostaglandins in varicocele patients. Fertil Steril 1982:37;218-22.

21. Lipshultz LI, Corriere JN. Progressive testicular atrophy in the varicocele patient. J Urol 1977;117:175.

22. Zini A, Buckspan M, Berardinucci D, Jarvi K. The influence of clinical and subclinical varicocele on testicular volume. Fertil Steril 1997;68:671-4.

23. Johnsen SG, Agger P. Quantitative evaluation of testicular biopsies in varicocele. Fertil Steril 1978;29:52-7.

24. Dubin L, Hotchkiss RS. Testis biopsy in subfertile men with varicocele. Fertil Steril 1969;20:50-7.

25. Ibrahim AA, Awad HA, El-Haggar S, et al. Bilateral testicular biopsy in men with varicocele. Fertil Steril 1977;28:663-7.

26. Johnsen SG, Agger P. Quantitative evaluation of testicular biopsies before and after varicocelectomy. Fertil Steril 1978;29:58-63.

27. Terquem A, Dadoune JP. Morphological findings in varicocele: An ultrastructural study of 30 bilateral testicular biopsies. Int J Androl 1981:4:515-31.

28. Comhaire F, Vermeulen A. Plasma testosterone in patients with varicocele and sexual inadequacy. J Clin Endocrin Metab $1975 ; 40: 824-9$

29. Su LM, Goldstein M, Schlegel PN. The effect of varicocelectomy on serum testosterone levels in infertile men with varicoceles. J Urol $1995 ; 154: 1752-5$

30. Macleod J. Seminal cytology in the presence of varicocele. Fertil Steril 1965;16:735-7.

31. Ali JI, Weaver DJ, Weinstein SH, et al. Scrotal temperature and semen quality in men with and without varicocele. Arch Androl 1989:24:215-9.

32. Naftulin BN, Samuels SJ, Hellstrom WJG, et al. Semen quality in varicocele patients is characterized by tapered sperm cells. Fertil Steril 1991:56:149-51.

33. Rodriguez-Rigau LJ, Smith KD, Steinberger E. Varicocele and the morphology of spermatozoa. Fertil Steril 1981;35:54-7. 
34. Ayodeji $\mathrm{O}$, Baker HW. Is there a specific abnormality of sperm morphology in men with varicoceles? Fertil Steril 1986;45:839-42.

35. Howards SS. Subclinical varicocele. Fertil Steril 1992;57:725-6.

36. Russell JK. Varicocele, age, and fertility. Lancet 1957;ii:222.

37. Nagler HM, Li X-Z, Lizza EF, Deitch A, White RD. Varicocele: Temporal considerations. J Urol 1985;134:411-3.

38. Chehval MJ, Purcell MH. Deterioration of semen parameters over time in men with untreated varicocele: Evidence of progressive testicular damage. Fertil Steril 1992;57:174-7.

39. Schlesinger MH, Wilets IF, Nagler HM. Treatment outcome after varicocelectomy: A critical analysis. Urol Clin North Am 1994:21:517-29.

40. Peterson AC, Lance RS, Ruiz HE. Outcomes of varicocele ligation done for pain. J Urol 1998;159:1565-7.

41. Yaman O, Ozdiler E, Anafarta K, Gogus O. Effect of microsurgical subinguinal varicocele ligation to treat pain. Urology 2000;55:107-8.

42. Kass EJ, Belman AB. Reversal of testicular growth failure by varicocele ligation. J Urol 1987;137:475.

43. Kass EJ, Freitas JE, Bour JB. Adolescent varicocele: Objective indications for treatment. J Urol 1989;142:579-82.

44. Kass EJ, Marcol B. Results of varicocele surgery in adolescents: A comparison of techniques. J Urol 1992;148:694-6.

45. Marmar JL, Kim Y. Subinguinal microsurgical varicocelectomy: A technical critique and statistical analysis of semen and pregnancy data. J Urol 1994;152:1127-32.

46. Goldstein M, Gilbert BR, Dicker AP, Dwosh J, Gnecco C. Microsurgical inguinal varicocelectomy with delivery of the testis: An artery and lymphatic sparing technique. J Urol 1992;148:1808-11.

47. Kamal KM, Jarvi K, Zini A. Microsurgical varicocelectomy in the era of art: Influence of initial semen quality on pregnancy rates. Fertil Steril 2001;75:1013-6.

48. Nilsson S, Edvinsson A, Nilsson B. Improvement of semen and pregnancy rate after ligation and division of internal spermatic vein: Fact or fiction? Br J Urol 1979;51:591-6.

49. Laven JS, Haans LC, Mali WP, et al. Effects of varicocele treatment in adolescents. Fertil Steril 1992;58:756-62.

50. Nieschlag E, Hertle L, Fischdick A, Abshagen K, Behre HM. Treatment of varicocele: Counseling as effective as occlusion of the vena spermatica. Human Reprod 1995;10:347-53.

51. Nieschlag E, Hertle L, Fischdick A, Abshagen K, Behre HM. Update on treatment of varicocele: Counseling as effective as occlusion of the vena spermatica. Human Reprod 1998;13:2147-50.

52. Madgar I, Weissenberg R, Lunenfeld B, Karasik A, Goldwasser B. Controlled trial of high spermatic vein ligation for varicocele in infertile men. Fertil Steril 1995;63:120-4.

53. Matthews GJ, Matthews ED, Goldstein M. Induction of spermatogenesis and achievement of pregnancy after microsurgical varicocelectomy in men with azoospermia and severe oligospermia. Fertil Steril 1998;70:71-5.
54. Kim ED, Leibman BB, Grinblat DM, Lipshultz LI. Varicocele repair improves semen parameters in azoospermic men with spermatogenic failure. J Urol 1999;162:737-40.

55. Szabo R, Kessler R. Hydrocele following internal spermatic vein ligation: A retrospective study and review of the literature. J Urol 1984;132:924-5.

56. Silber S. Microsurgical aspects of varicocele. Fertil Steril 1979;31:230-2.

57. Wosnitzer M, Roth JA. Optical magnification and Doppler ultrasound probe for varicocelectomy. Urology 1983;22:24-6.

58. Penn I, Mackie G, Halgrimson CG, Starzl TE. Testicular complications following renal transplation. Ann Surg 1972;176:697-9.

59. Gorenstein A, Katz S, Schiller M. Varicocele in children: "To treat or not to treat" - venographic and manometric studies. J Pediatr Surg 1986;21:1046-50.

60. Levitt S, Gill B, Katlowitz N, et al. Routine intraoperative postligation venography in the treatment of the pediatric varicocele. J Urol 1987;137:716-8.

61. Reitelman C, Burbige KA, Sawczuk IS, Hensle TW. Diagnosis and surgical correction of the pediatric varicocele. J Urol 1987;138:1038-40.

62. Kaufman SL, Kadir S, Barth KH, et al. Mechanisms of recurrent varicocele after balloon occulusion or surgical ligation of the internal spermatic vein. Radiology 1983;147:435-40.

63. Homonnai ZT, Fainman N, Engelhard Y, Rudberg Z, David MP, $\mathrm{Paz}$ G. Varicocelectomy and male fertility: Comparison of semen quality and recurrence of varicocele following varicocelectomy by two techniques. Int J Androl 1980;3:447-56.

64. Rothman LP, Newmark M, Karson R. The recurrent varicocele. A poorly recognized problem. Fertil Steril 1981;35:552-6.

65. Murray RR, Mitchell SE, Kadir S, et al. Comparison of recurrent varicocele anatomy following surgery and percutaneous balloon occlusion. J Urol 1986;135:286-9.

66. Sayfan J, Adam YG, Soffer Y. A natural "venous bypass" causing postoperative recurrence of a varicocele. J Androl 1981;2:108-10.

67. Sayfan J, Adam YG, Soffer Y. A new entity in varicocele subfertility: The "cremasteric reflux". Fertil Steril 1980;33:88-90.

68. Mitchell SE, White RI, Chang R, et al. Long-term results of outpatient balloon embolotherapy in 300 varicoceles. Radiology 1985;157(Suppl):90.

69. Matthews RD, Roberts J, Walker WA, Sands JP. Migration of intravascular balloon after percutaneous embolotherapy of varicocele. Urology 1992;49:373-5.

70. Bonduelle M, Camus M, DeVos A, et al. Seven years of intracytoplasmic sperm injection and follow-up of 1987 subsequent children. Hum Reprod 1999;14(Suppl):243-64

71. Schlegel PN. Is assisted reproduction the optimal treatment for varicocele-associated male infertility? A cost-effectiveness analysis. Urology 1997;49:83-90. 